\title{
ARTIGO
}

\section{MÉTODO DE ALFABETIZACÃO GLOBAL DE CONTOS E O PAPEL DA LEITURA COMO RENOVAÇÃO DAS PRÁTICAS E MODERNIDADE PEDAGÓGICA (1918-1938)}

\author{
GEISA MAGELA VELOSO - (https://orcid.org/0000-0002-7392-2749) * \\ Universidade Estadual de Montes Claros, Montes Claros, MG, Brasil \\ APARECIDA PAIVA - (https://orcid.org/0000-0001-7275-9209) * * \\ Universidade Federal de Minas Gerais, Belo Horizonte, MG, Brasil \\ CYNTHIA GREIVE VEIGA - (https://orcid.org/0000-0002-7634-6767) *** \\ Universidade Federal de Minas Gerais, Belo Horizonte, MG, Brasil
}

RESUMO: $\mathrm{O}$ artigo tem por objetivo identificar representações sobre o método de alfabetização global de contos, analisando o papel da leitura no processo de renovação das práticas de ensino e na instauração da modernidade. Tomando o jornal Gazeta do Norte como fonte documental, constatou-se que a cidade de Montes Claros - MG fez adesão à Reforma Francisco Campos (1927-1928), que impôs o método global de contos para alfabetizar com base na compreensão dos textos e não apenas na memorização de unidades linguísticas. Os discursos disseminados ainda indicam que o ensino da leitura deveria possibilitar a pesquisa, a reflexão e o uso da linguagem em diferentes situações comunicativas.

Palavras-chave: Método global de contos; Leitura compreensiva; Modernidade pedagógica; Práticas alfabetizadoras.

\section{METHOD OF GLOBAL LITERACY THROUGH SHORT STORIES AND THE ROLE OF READING AS A RENEWAL OF PRACTICE AND PEDAGOGICAL MODERNITY (1918-1938)}

ABSTRACT: This article aims to identify representations about the global method of literacy through short stories, analyzing the role of reading in the process of renewal of teaching practices and the establishment of pedagogical modernity. Taking the newspaper 'Gazeta do Norte' as a document source, we found that the city of Montes Claros, Minas Gerais,

\footnotetext{
* Geisa Magela Veloso é professora associada da Universidade Estadual de Montes Claros/ Unimontes, pesquisadora do GEPEL - Grupo de Estudo e Pesquisa em Educação e Linguagem da Unimontes; Doutora em Educação pela Universidade Federal de Minas Gerais/ UFMG. E-mail:< velosogeisa@gmail.com> .

** Aparecida Paiva é professora associada da Universidade Federal de Minas Gerais (UFMG), pesquisadora do CEALE - Centro de Estudos em Alfabetização, Leitura e Escrita da UFMG; Doutora em Literatura Comparada pela Universidade Federal de Minas Gerais (UFMG). Email:<paiva.aparecida@gmail.com >.

*** Cynthia Greive Veiga é professora titular da Universidade Federal de Minas Gerais (UFMG), pesquisadora do GEPHE - Grupo de Estudo em História da Educação da UFMG; Doutora em História pela Universidade Estadual de Campinas (Unicamp). Email:<greive@fae.ufmg.br >.
} 
joined the Francisco Campos Reform (1927-1928) which imposed the global method of short storiesto teach how to read and write based on the understanding of texts not only in the memorization of linguistic units. The disseminated speeches also indicate that reading teaching should enable research, reflection and language use in different communicative situations.

Keywords: Global method of short stories; Comprehensive Reading; Modern teaching; Literacy practices.

\section{INTRODUCุ̃̃O}

$\mathrm{O}$ artigo ${ }^{1}$ discute facetas da história da educação em Montes Claros-MG e tem por objetivo identificar representações sobre o método de alfabetização global de contos, analisando o papel da leitura no processo de renovação das práticas de ensino e na instauração da modernidade.

A pesquisa situa-se no âmbito da História Cultural, na vertente proposta por Chartier (1990), que entende a historiografia como processo pelo qual se pode reconstituir o modo como, em diferentes lugares e momentos, uma determinada realidade social é construída, pensada, dada a ler. Para o autor, a história cultural é a história das representações - consideradas como matrizes geradoras de discursos e práticas, representações que não são a verdade, mas aquilo que o sujeito pensa que é o real ou aquilo que ele gostaria que fosse.

Por essa orientação, realizamos uma incursão histórica na cidade de Montes Claros, não pela crença em acontecimentos verdadeiros, mas pela busca de representações, de forma a mapear significações e apropriações que constituíram um emaranhado de ações e práticas, atitudes e gestos. Como fontes documentais, utilizamos o jornal Gazeta do Norte, uma publicação periódica da cidade de Montes Claros, que circulou entre os anos de 1918 e 1962. Instalado em Montes Claros pelo advogado José Thomaz de Oliveira, no mês de julho de 1918, por ocasião do $39^{\circ}$ aniversário da cidade, o jornal Gaz̨eta do Norte se identificava como um "semanário independente, literário e noticioso" e permitiu captar as especificidades locais, mapear ocorrências em curso na região Norte Mineira, discutir saberes postos em circulação.

Ao discutir os jornais como fonte documental, Zicman (1985, p.90) aponta que a sua periodicidade diária apresenta-se como vantagem, por transformá-los em "arquivos do quotidiano" a registrar a memória do dia a dia e possibilitar uma cronologia dos fatos. Por isso, o jornal é pressionado a buscar e dar publicidade às ocorrências cotidianas. No caso da Gaz̧eta do Norte, possivelmente em função de sua periodicidade semanal, o jornal não era sentia a imperiosa 
necessidade de dar a ver os acontecimentos e mostrar-se atualizado. Assim, secundariza-se o seu caráter noticioso, para priorizar a discussão de temas e questões do seu tempo, visando formar a opinião pública, colaborar com a construção de uma nova mentalidade, instaurar o progresso e a modernidade pela disseminação de ideias. As matérias publicadas abordavam diversas temáticas, sobretudo, questões políticas, econômicas e sociais. No entanto, o jornal também conferiu grande visibilidade para a educação, publicizando questões culturais e educacionais. Especificamente em relação à educação e instrução, no período tomado como referência para o estudo (1918-1938), identificamos 178 matérias de natureza informativa ou formadora de opinião; 71 publicações em que os eventos da Escola Normal Oficial de Montes Claros foram produzidos como notícia; 30 conferências médicas ou pedagógicas, transcritas na íntegra ou em versão resumida; 19 matérias de cunho pedagógico, discutindo conceitos e concepções educacionais, metodologias e práticas de ensino. Cerca de $2 / 3$ destas publicações receberam destaque na primeira página, indicando a relevância do tema educação para o jornal.

Em nosso estudo, para ampliar a análise da realidade e captar a sincronia do movimento local com as ocorrências mais amplas, como fontes complementares, utilizamos a Revista do Ensino publicação oficial do governo de Minas Gerais criada no ano de 1925 com a finalidade de disseminar ideais renovadores.

Como recorte temporal, trabalhamos como período de 1918 a 1938 - opção orientada por questões locais e referenciadas por ocorrências ligadas a Montes Claros. De forma específica, o recorte temporal se circunscreve pelo ano de fundação do jornal Gazeta do Norte - tomado como objeto de estudo e principal fonte documental - e o ano de extinção da Escola Normal Official de Montes Claros, que exerceu grande influência na disseminação de ideias e alimentou as publicações do jornal. Ainda que o recorte tenha considerado as especificidades locais, não desconhecemos as forças políticas, sociais, econômicas e culturais que moveram a sociedade brasileira. As décadas de 1920-30 se constituem como um tempo histórico singular, em que foram gestadas e implementadas propostas de modernização do Brasil, em que a cidade de Montes Claros imaginou para si um ideal de futuro e procurou inserir-se nesse contexto moderno.

No contexto global, vale destacar que, por influência europeia e norte-americana, estava em curso um processo de renovação proposto pela Escola Nova, que instaura um movimento de mudança nos discursos e práticas educativas. No Brasil, a necessidade da 
alfabetizar e instruir a população integrou os discursos disseminados desde o final do século XIX, por esta ser considerada uma condição para a modernidade, o progresso e o desenvolvimento individual e social. No âmbito estadual, Minas Gerais redefine sua política educacional e implanta a Reforma Francisco Campos em 192728, adotando princípios escolanovistas como sentido da renovação pretendida. Nesse cenário de mudanças, a Escola Normal Official de Montes Claros constituiu-se como lugar de apropriação desses conhecimentos e produção de representações e ideais educativos, encontrando no jornal Gazeta do Norte um espaço privilegiado para sua circulação, visando modernizar a cidade e favorecer seu desenvolvimento. Ou seja, o jornal apresenta-se como espaço de opinião pública, capaz de ampliar a capacidade de fazer ouvida a voz dos intelectuais montes-clarenses; enquanto a Escola Normal tornase referência e inspiração para a produção de concepções e ideias modernas, que visavam à mudança nas mentalidades e sociabilidades.

Conforme Graff (1997), desde a primeira metade do século XIX, a alfabetização e as habilidades de ler e escrever tornaram-se fundamento e inspiração para as mudanças nas culturas ocidentais. Para essas sociedades, e ainda hoje, a educação e a escolarização eram determinantes para o desenvolvimento, creditando-se à leitura e à escrita a capacidade de produzir impactos individuais e sociais. Por essa compreensão, a alfabetização e o uso social da leitura e da escrita apresentaram-se como motor de mudanças em seus usuários, do ponto de vista cognitivo, político, econômico, social e cultural; sendo que, para as sociedades, seria considerado um traço da modernidade, uma condição para a civilização e o progresso.

Ao discutir práticas de leitura, Hébrard (1996) considera que, desde as propostas de reforma no Século das Luzes até as expansões escolares do século XIX, todas as políticas educativas estavam plenamente convencidas de que o ensino da leitura era um meio de transformar os valores e os hábitos dos grupos sociais. Para o autor, a crença era de que o livro presta-se aos rituais de coesão social, familiar ou mais ampla, podendo interpelar o leitor e interferir na sua formação (HÉBRARD, 1996). Pela mesma lógica, Certeau (1998) afirma que, "a ideia de uma produção da sociedade por um sistema 'escriturístico' não cessou de ter como corolário a convicção de que, com mais ou menos resistência, o público é moldado pelo escrito (verbal ou icônico)", permitindo que as ideias do texto sejam impressas no leitor (1998, p. 261 - ênfase do autor).

Por essa representação positiva sobre os benefícios individuais e sociais proporcionados pelas habilidades de ler e escrever, a defesa 
da escolarização constitui-se como verdadeira bandeira assumida por diferentes sociedades. É nesse contexto que situamos a cidade de Montes Claros e sua busca por modernidade e desenvolvimento.

Neste artigo, inicialmente, discutimos as defesas em favor da adoção do método global de contos, no âmbito da Escola Nova. Na seção seguinte, discutimos a necessidade de produção de materiais didáticos orientados pela abordagem analítica como condição para as mudanças nas práticas alfabetizadoras. Na terceira seção, a leitura é tematizada como recurso para aprendizagem e aquisição de conhecimentos, por uma preocupação com o ensino contextualizado da linguagem, atrelado aos interesses e necessidades expressivas dos alunos, que incluía a leitura, a oralidade e também a escrita. Na quarta seção, os livros e a leitura de história são tomados como objeto de discussão, por representações que têm o desejo, o interesse e o prazer da criança como molas propulsoras da atividade e da busca pelos livros, também sinalizando para a interdição de livros inadequados à formação das crianças.

\section{A DEFESA DO MÉTODO GLOBAL DE CONTOS NO ÂMBITO DA ESCOLA NOVA}

No contexto das décadas de 1920-30 a adoção de princípios da Escola Nova representava a modernidade pedagógica. Conforme Lourenço Filho (1978), a expressão Escola Nova não se refere a um tipo de escola, mas a um conjunto de princípios que visavam à revisão de formas tradicionais de ensino. Apesar de disseminado no Brasil nas primeiras décadas do século XX, o movimento escolanovista teve origem nos últimos anos do século XIX - momento em que educadores de vários países discutem os problemas educacionais tentando resolvê-los pela aplicação das recentes descobertas da ciência, sendo que as primeiras "escolas novas" surgem na Europa como instituições privadas de ensino (LOURENÇO FILHO, 1978).

Em Minas Gerais, a adoção de princípios da Escola Nova foi institucionalizada pela Reforma Francisco Campos (1927-1928), implementada pelo Regulamento do Ensino Primário (Decreto lei 7.970, de 15 de outubro de 1927) e complementada pelo Regulamento do Ensino Normal (Decreto lei 5.162, de 20 de janeiro de 1928) e pelos Programas do Ensino Primário (Decreto lei 8.094, de 20 de janeiro de 1928). Conforme Frade e Maciel (2006), para viabilizar a implementação da reforma foi criada a Escola de Aperfeiçoamento em Belo Horizonte, além de 21 outras escolas normais oficiais no interior do Estado; foram promovidos cursos e palestras, instaladas 
bibliotecas escolares e intensificada a divulgação da Revista do Ensino para disseminar as inovações pedagógicas.

Ainda conforme as autoras, a Reforma Francisco Campos demarcou disputas por métodos de alfabetização e interferiu no processo de ensino desenvolvido nas escolas mineiras. A proposta de reforma era abrangente, teve a inovação metodológica como eixo e produziu uma mudança paradigmática em relação ao aprendizado da leitura e da escrita, negando os métodos sintéticos e prescrevendo a adoção do método global de contos para alfabetização. Por esse motivo, o ano de 1927 é considerado um marco de mudança para o ensino e para a história da alfabetização em Minas (FRADE; MACIEL, 2006).

A Revista do Ensino, como órgão oficial do governo mineiro encarregado da disseminação de propósitos reformadores, em diferentes artigos colocou em circulação esses debates em torno dos métodos. Ainda em 1928, Júlio de Oliveira fez a defesa da alfabetização pelo método ideovisual de Decroly, que partia da sentença, tinha por base a exploração das ideias contidas no texto e visava à formação de conceitos no espírito da criança. Sendo um "método ideológico", não deveria ser confundido com o método da "fraseação", isso porque, levar o aluno a "decorar um trecho ou uma phrase e depois decompol-o em palavras e syllabas, não é o mesmo que formar idéas para depois expressal-as", sendo importante selecionar textos coerentes e trabalhar as significações presentes (OLIVEIRA, 1928, p. 100).

Em 1929, Firmino Costa, Director Técnico do Curso de Aplicação da Escola Normal Modelo de Belo Horizonte, defende o método de alfabetização idealizado por Decroly, denominado de "ideo-visual porque a imagem graphica está sempre intimamente ligada à scena ou ao objecto; global, porque apresenta o todo". Além de favorecer a compreensão dos conteúdos presentes no texto e não meramente a decifração do código, o método ideo-visual era considerado como mais adequado ao processo de pensamento e percepção da criança, que era globalizante (COSTA, 1929, p. 44).

Em defesa do método global de contos, Lucia Schimidt Monteiro destaca suas vantagens, já "demonstradas cientificamente", salientando que os métodos sintéticos produziam a memorização de fragmentos e uma leitura mecânica das palavras, em contraponto à leitura inteligente e a compreensão dos textos (MONTEIRO, 1930a, p. 48).

No contexto montes-clarense, discussão semelhante ocorreu alguns anos mais tarde, em 1933, momento em que o jornal Gazeta do Norte e a Escola Normal local passaram a defender a alfabetização pelo método global de contos, compreendido como mais adequado 
à aquisição das habilidades de leitura e escrita esperadas dos cidadãos modernos. Ao prescrever a utilização das abordagens analíticas, a Gazeta do Norte rejeita os métodos sintéticos e sinaliza que a nova metodologia proposta é um modo de ensino que tem a compreensão por base, partindo da palavra ou de unidades maiores para sistematizar a alfabetização. Em artigo publicado pelo jornal, Alberto Conte destaca a importância dos métodos de ensino, cujo valor não se media pela quantidade de conhecimentos que possibilitavam transmitir, mas pelo seu coeficiente educativo.

O methodo syntetico de ensino de leitura, por exemplo, é talvez mais rápido que o methodo analytico, e este, no ensino não globalizado, mais rápido que o aprendizado da leitura no ensino globalizado. Mas o que importa isso, se esse último é o mais educativo, o que mais desenvolve e fórma o espírito? (CONTE, 1933, p. 02).

A defesa da qualidade da alfabetização já havia sido discutida pela Revista do Ensino, em 1930, quando a professora Lúcia Schimidt Monteiro aborda a suposta maior eficiência dos métodos sintéticos, contrapondo o argumento da rapidez com o da superioridade da aprendizagem pelo método global de contos.

O methodo global, como está demonstrado scientificamente, é superior ao fonético - Experiencias levadas a efeito por alemães e norte-americanos demonstraram que as creanças têm percepção syncretica das coisas - É certo que o processo phonetico dará nos três primeiros mezes resultado apparentemente superior ao global, mas na verdade inferior, como se tem seguramente verificado (MONTEIRO, 1930a, p. 48).

Por essa lógica, a escolha adequada do método de alfabetização produziria consequências para aprendizado da leitura e para a formação integral do aluno. Em 1933, artigo de Helena Santos, aluna do Curso de Aplicação da Escola Normal Official de Montes Claros reafirma a supremacia do método global, por ser coerente com os processos de organização mental, ação e expressão da criança.

"A creança age e expressa por sintheses". Chegou-se, pois, à conclusão de que a leitura deve acompanhar essas estructuras ou sintheses a ser ensinada pelo processo global. Ministrando esse ensino, devem ser observados dois fins; um intrínseco, próprio da leitura, que consiste em dotar o alumno do mecanismo dos signaes graphicos, e outro extrínseco, próprio de educação, que é a formação de hábitos de leitura para a aquisição de experiências relativas a todas as actividades do ensino (SANTOS, 1933, p. 01 - ênfases no original).

A aluna considera que a alfabetização não deveria circunscreverse à decifração, mas possibilitar a leitura compreensiva, em que a atividade de ler os textos favorecesse o acesso a outros conhecimentos escolares. 
Este é um posicionamento que revela concepções da época e foi discutido pela Revista do Ensino, no ano de 1930. Para a professora Lucia Schimidt Monteiro, a aquisição da leitura constituía-se como ferramenta importante para a aprendizagem dos conhecimentos escolares:

É necessário que a escola ensine e habitue antes de tudo os alunos a se servirem da leitura como instrumento para a acquisição de experiências - As duas ou três primeiras semanas de escolaridade devem ser preenchidas com exercícios e actividades tendentes a convencerem aos alunos da necessidade de aprenderem a lêr (MONTEIRO, 1930a, p. 48).

Ainda em defesa do método global de contos, no ano de 1931, a Revista do Ensino aponta as desvantagens dos métodos sintéticos, por não colocarem ênfase na interpretação, que é a principal atitude exigida no método global; não favorecerem as antecipações de ideias e não despertarem o interesse pela leitura. E esta foi uma questão que dividiu opiniões, opôs defensores dos métodos sintéticos e analítico global de contos.

\section{A PRODUĈ̣̃O DE PRÉ-LIVROS GLOBAIS COMO CONDIC̣ÃO PARA A RENOVAC̣ÃO DO ENSINO}

Na seção anterior mostramos que, nas disputas por métodos de alfabetização, duas questões básicas orientavam os posicionamentos. De um lado, a aparente maior rapidez na alfabetização era a vantagem atribuída aos métodos sintéticos; por outro lado, a educação integral e a possibilidade de compreensão dos textos, desde o início do processo de aprendizagem da leitura, apontavam a supremacia do método global de contos. No entanto, contra a mudança e a favor da permanência dos processos de alfabetização sintéticos, havia outro elemento gerador de dificuldades: os professores não dominavam as etapas para aplicação do método global, precisavam trilhar caminhos desconhecidos e abrir mão de saberes já construídos na prática. Até então, em suas práticas alfabetizadoras, as professoras utilizavam as cartilhas sintéticas, que haviam sido introduzidas no Brasil desde o século XIX, cuja metodologia era amplamente conhecida.

Ao discutirem o contexto de implementação da Reforma Francisco Campos em Minas Gerais, Frade e Maciel (2006) afirmam que a adoção do método analítico global de contos gerou insegurança entre as professoras. O maior entrave estava na falta de suporte pedagógico, pois as professoras foram obrigadas a adotar uma 
proposta metodológica para a qual não estavam preparadas e não dispunham de material didático. Acostumadas ao uso de cartilhas, repentinamente, as professoras viram-se sem suporte pedagógico para ministrarem suas aulas.

Ainda segundo as autoras, procurando atender às reivindicações e críticas das professoras e precavendo-se da insatisfação com os rumos da reforma, a Escola de Aperfeiçoamento promoveu um concurso entre suas alunas. A escola fora criada em 1929 para formar multiplicadores de metodologias e difundir o ideário renovador, sendo que o concurso, organizado pela professora Lúcia Casasanta, inseriu-se nesse contexto e visou à produção de manuais didáticos que seguissem os pressupostos teórico-metodológicos do método global de contos. Essa nova produção didática recebeu o nome de "pré-livro", tinha o mesmo objetivo das cartilhas sintéticas e foi testada nas Classes de Demonstração da Escola de Aperfeiçoamento, em Belo Horizonte. Algumas das produções das normalistas em formação tornaram-se sucesso editorial, como é o caso de $O$ livro de Lili, de Anita Fonseca, Bonequinho Doce, de Alaíde Lisboa de Oliveira, A Pituchinha, de Marieta Leite (FRADE; MACIEL, 2006).

Em Montes Claros, não foi possível constatar se as professoras resistiram à adoção do método global de contos pela falta de material didático. Contudo, em 1933, o jornal Gazeta do Norte publicou matéria que explicava o significado e a importância do pré-livro. Por valorizar o ensino da leitura como experiência global, Helena Santos, aluna do Curso de Aplicação da Escola Normal, defendeu a necessidade de cuidado especial na elaboração desse material de ensino da leitura.

O Pré-livro, a respeito do qual fazemos algumas observações, é constituído pelas lições organizadas pela professora para o tempo correspondente aos primeiros mezes do anno lectivo, nas classes de analphabetos. Compõe-se de pequenas histórias, em numero de três ou mais, contribuindo cada uma para o reconhecimento de todas as palavras que a compõem (SANTOS, 1933, p. 01).

A preocupação principal era que a criança aprendesse o código escrito pela compreensão dos significados inscritos nos textos e pelo reconhecimento global das palavras. Daí a importância de histórias curtas e ilustradas que facilitassem a reconstituição e interpretação das ideias, cujo trabalho seria complementado por jogos e fichas para identificação de elementos linguísticos e reconstituição das palavras, frases e texto.

Organizadas essas histórias, que devem ser amplamente illustradas com gravuras coloridas e dynamicas, suggestivas e dramatizáveis, completar-se-á o material com fichas relativas às histórias, às phrases, às palavras, às sylabas para os jogos de reconhecimento e reconstituição (SANTOS, 1933, p. 01). 
Para cumprir a função de favorecer o desenvolvimento integral da criança, a professora não poderia dedicar o tempo de aula exclusivamente às atividades para alfabetização, mas integrá-las ao trabalho com os demais conteúdos previstos pelo currículo escolar.

Geralmente, ao preparar seu Pré-livro, preocupa-se a professora com a leitura de modo exclusivo, esquecendo-se de que o ensino é hoje feito em situação total e globalmente. Durante as aulas occupa o tempo com a história, a escripta das palavras e o desenho da gravura, mudando completamente de assumpto quando se lembra de que a educação do alumno exige experiências ligadas a outras matérias do programma. Neste caso sente mesmo difficuldades insuperáveis e usa então do processo de occupar os primeiros meses do anno apenas com a leitura, a escripta e o desenho (SANTOS, 1933, p. 01).

Por essa visão, o tempo da alfabetização deveria vincular-se às demais atividades de ensino, não representar um corte no processo de educação, mas inserir-se no currículo. O material destinado ao ensino da leitura deveria servir para estabelecer associações entre os conteúdos e interligar as experiências escolares. As histórias não eram um mero apoio à decifração do código escrito, posto que compreendidas como recursos educativos, textos para leitura imbuídos de significados. A leitura não deveria ser entendida como um fim, mas como atividade meio, estratégia que favoreceria a vivência de experiências e a obtenção de novos conhecimentos. Ensinar a ler como fim em si mesmo era considerado um grave defeito da pedagogia.

Como sanar esse defeito? Compenetrando-se de que todo o ensino é global e compreende todas as disciplinas do curriculum; escolhendo histórias e gravuras que se prestem à aprendizagem de maior numero de matérias; dividindo o tempo de aulas de modo que sejam contempladas outras matérias e não apenas a linguagem, a escripta e o desenho (SANTOS, 1933, p. 01).

A atividade de ensino deveria adequar-se às demandas por leitura. $\mathrm{O}$ ato de ler implicava antecipar sentidos e compreender as ideias após realizar a leitura. A professora deveria utilizar as gravuras como suporte para a compreensão das ideias e interpretação dos textos de forma global.

Ha, de um modo geral, no Pré-livro um todo que encerra uma idea da qual a creança passa às partes. Desta forma a compreensão do todo deve preceder à leitura. A antecipação de idea é feita por duas imagens: uma illustrativa, provocada pela gravura, outra significativa, pela comprehensão do quadro. Esse conjuncto é que forma o processo global da leitura, a qual deve ser em situação total, isto é, lançando mão de todas as forças psychicas que dão actividade e acção ao pensamento (SANTOS, 1933, p. 01). 
Por esse discurso, percebe-se a importância atribuída ao conteúdo, às ilustrações, aos sentidos veiculados pelos textos e à compreensão destes pelo alfabetizando. Por ser uma atividade meio, não bastava aprender a ler, a leitura deveria apresentar-se como instrumento necessário ao aprendizado de outros conteúdos. Ou seja, ao mesmo tempo em que aprendia a decifração, o aluno compreenderia os textos e aprenderia novos conhecimentos pela via da leitura das histórias e gravuras.

Decifração e sentido foram aspectos centrais nessas discussões sobre métodos de alfabetização e, conforme Frade (2004), a materialização dessa polarização girou em torno de dois modelos de livros: as cartilhas sintéticas com foco na decifração e os pré-livros globais que enfatizavam a compreensão. No entanto, para a autora, o método global de ensino teve que fazer concessão à decifração, mesmo quando esse processo não aparecia claramente no corpo dos livros, que aparentemente eram apenas de leitura.

Ainda conforme Frade (2004), as definições de método extrapolam o enquadramento e a materialização no suporte livro didático. No entanto, uma estreita vinculação entre livro e método é facilmente percebida na história da alfabetização brasileira, em que o método está inscrito nas atividades, em que o livro representa o modo de fazer. Ou seja, os métodos são depreendidos e compreendidos na sua materialização em livro, e a maioria das atividades desenvolvidas em sala de aula é sugerida pelos autores desses livros (FRADE, 2004). Por isso, ao tomar a cartilha como base para a alfabetização, as professoras não precisavam compreender a lógica de organização do método, nem planejar uma sequência didática a ser desenvolvida em aula. $\mathrm{Na}$ prática, bastava seguir as atividades propostas no livro, fazendo ajustamentos aos interesses dos alunos.

Nesse sentido, é possível compreender a insegurança, as possíveis resistências, como também a preocupação da Escola de Aperfeiçoamento, em produzir e testar livros de alfabetização orientados pelo método global. Pela mesma perspectiva, também entendemos as preocupações do jornal Gazeta do Norte que, em sua missão educativa, orientou as professoras primárias na elaboração e uso de pré-livros globais. As críticas das normalistas montesclarenses foram endereçadas às práticas alfabetizadoras desenvolvidas nas escolas primárias, centradas na decifração e traçado das letras, desarticuladas da compreensão dos textos e das disciplinas do currículo. Também podemos compreender as orientações sobre a alfabetização global, para que as professoras pudessem selecionar 
ilustrações e textos, produzir seu pré-livro para ensino da leitura e o material complementar para análise linguística.

Para as professoras era mais cômodo alfabetizar com os métodos sintéticos, não apenas porque dominavam a metodologia e já haviam produzido saberes pedagógicos, mas pela possibilidade de utilizar as cartilhas e ter o livro como base de organização de suas aulas. Ao discutir o uso de livros didáticos, Anne Marie Chartier considera que "os manuais de leitura programam, geralmente, uma pedagogia coletiva, através de uma progressão única, cuja vantagem é fazer da turma uma comunidade de trabalho". Isso porque todos os alunos fazem as mesmas leituras e atividades, que se tornam uma experiência compartilhada e constitui uma memória do grupo (CHARTIER, 2007, p. 156). Nessa direção, Frade (2004) considera que o livro didático pode ser considerado como um dispositivo organizativo, que vai além dos conteúdos disciplinares, pode possibilitar a homogeneização e individualização, por um processo em que a escola ensina a todos ao mesmo tempo, como se fosse a um só.

No contexto da Reforma Francisco Campos, a mudança não se restringia à adoção dos métodos globais, mas também à necessidade de rever as finalidades que a leitura assumia para o leitor. Não bastava mudar a orientação inicial do ensino, deixar de focalizar a sílaba, a letra ou o som como ponto de partida do ensino e passar a considerar a palavra, a frase, o conto ou a historieta. Mais do que mudar o eixo de abordagem do código escrito era necessário mudar todo o processo de ensinar, focalizando as ideias, os sentidos inscritos nas unidades linguísticas tomadas como referência. Não apenas o método de ensino era questionado, estava em jogo a finalidade do ensino da leitura.

\section{LEITURA COMORECURSOPARA APRENDIZAGEMEAQUISIÇÃODECONHECIMENTOS}

No contexto montes-clarense, constatamos que, desde os últimos anos da década de 1920, o jornal Gazeta do Norte e a Escola Normal local produziram um refinamento nas discussões sobre o saber ler e o escrever, que não se circunscrevia à mera alfabetização. $\mathrm{Na}$ década de 1930, os ideais escolanovistas definem um novo cenário, com ampliação das funções atribuídas ao ensino, que deveria ser contextualizado em situações de uso da linguagem oral, da leitura e escrita. Pelos deslocamentos ocorridos, tornou-se necessário considerar a linguagem como objeto de ensino e instrumento de aquisição de conhecimentos e expressão de ideias. Para Idoleta Maciel, aluna do Curso de Aplicação da Escola Normal Official de Montes 
Claros, "a linguagem está em dupla relação com a obra educativa. Por uma parte é usada continuamente em toda disciplina social da escola e por outro lado é objecto especial de estudo" (MACIEL, 1933, p. 02).

Para Helena Santos, também aluna do Curso de Aplicação, as novas funções atribuídas à linguagem corresponderiam a um novo modo de ensinar. A leitura passou a ser compreendida como técnica para a decifração dos sinais gráficos e mecanismo de aquisição e transmissão de conhecimentos e experiências, recurso para pesquisa e investigação.

A aprendizagem da leitura tem por fim fornecer ao indivíduo, atravez de signaes grafhicos, uma technica ou mecanismo de acquisição e transmissão de conhecimentos, visando ainda, e principalmente, a creação de hábitos de investigação e pesquisa por meio da consulta aos livros. São esses seus objectivos, afastando-se dos quaes o professor deixa de dar a essa importante disciplina o caracter que realmente deve ter. Nos processos de investigação a leitura é um auxiliar do alumno na acquisição de novos conhecimentos, especialmente dos relativos às demaes matérias do curriculum, tornando-se necessário o aproveitamento desse mister para boa comprehensão de seu valor pelo alumno (SANTOS, 1933, p. 01).

Essa ampliação dos sentidos atribuídos ao aprendizado da leitura e escrita fazia parte das ideias renovadoras da época e já havia sido tratada pela Revista do Ensino, desde 1930, por José Raymundo Netto, Assistente Técnico do Ensino. Para ele, os Estados Unidos tinham inovado seu ensino, ampliando os currículos destinados às camadas populares para além do ler, escrever e contar, e o Brasil já se encaminhava na mesma direção. Em suas palavras:

Nós começamos, apesar das incréus ou rotineiras, a perlustrar essa mesma estrada palmilhada pelos Estados Unidos há 40 ou 50 annos; estamos no início da jornada, é bem certo, e temos deante de nós grandes obstáculos a vencer; mas também é certo que o movimento innovador toma vulto e vae ganhando corações, dia a dia (RAYMUNDO NETTO, 1930, p. 04).

$\mathrm{Na}$ década de 1930, o debate já indicava não ser suficiente apenas a alfabetização. Era necessário desenvolver habilidades de acesso ao mundo da escrita, compreensão dos textos, reflexão sobre seu conteúdo e aquisição de conhecimentos. Visando a mudança nas metodologias de ensino da leitura, no ano de 1933, a Revista do Ensino publica matéria de Levindo Lambert, que discute o ensino do canto nas escolas primárias, destacando que o ato de cantar deveria ser precedido da compreensão da letra da música. Ao criticar o ensino do canto, o olhar do professor não focaliza as habilidades musicais do aluno, mas a leitura e a compreensão do texto. Assim, o professor propõe um trabalho em que o cantar fosse precedido do interpretar e explicar o conteúdo e a forma do texto, para que as crianças soubessem o que estavam cantando (LAMBERT, 1933, p. 30). 
Ainda em 1933, o ensino da leitura é novamente destacado como elemento importante para a formação das crianças, sendo que a Revista do Ensino esperava que as escolas desenvolvessem ações de ampla propaganda da leitura, criação de bibliotecas e melhoria das já existentes (REVISTA DO ENSINO, 1933). Novamente em 1933, Adherbal Alvarenga afirma a necessidade de desenvolver habilidades mais refinadas de leitura. O professor considera que "um dos segredos do saber consiste em saber lêr. Uma leitura feita às pressas, como uma refeição rapidamente tomada, só póde ser indigesta, mas nunca assimilada" (ALVARENGA, 1933, p.64).

No contexto da cidade de Montes Claros, os artigos publicados pelo jornal Gazeta do Norte mostram que a leitura deveria ser atividade de pesquisa e investigação. Por isso, a escolha de textos deveria possibilitar um trabalho expressivo e reflexivo com a linguagem. Para Idoleta Maciel, aluna do Curso de Aplicação da Escola Normal:

\footnotetext{
Nada se conseguiria com acquisições theoricas e regras abstratas. O contacto íntimo com as bôas dicções e bons textos, em todas as actividades escolares, a prática dirigida pela preocupação reflexiva de expressar-se clara e belamente, podem conduzir a resultados magníficos no aprendizado da linguagem, a criança a ser educada (MACIEL, 1933, p. 02).
}

Era necessário ensinar a ler, mas considerar a interpretação dos textos e o desenvolvimento da linguagem como eixo orientador da atividade escolar. Exercitar e aperfeiçoar a capacidade de reflexão não poderia limitar-se às aulas de português, nem ser pensada como atividade de treino mecânico de habilidades.

Toda matéria é matéria de linguagem, e os professores devem, em qualquer aula, procurar melhorar e aperfeiçoar a linguagem dos seus alunos, não podendo contudo deixar o principal pelo acessório. Obedecendo mais ou menos a estas considerações é que deve ser feito o ensino da linguagem. Aprender uma língua não é simplesmente transmitir pensamentos. Comprehender é tarefa primordial e básica deste ensino, eliminando assim o psitacismo (MACIEL, 1933, p. 02).

Esses posicionamentos identificados em Montes Claros já haviam sido discutidos na Revista do Ensino, indicando que a linguagem deveria ser trabalhada em situações de uso e fosse uma necessidade expressiva das crianças.Em 1930, Lucia Schimidt Monteiro aponta a "necessidade de se estender a preocupação da linguagem a todas as matérias, não sendo Ella objecto exclusivo da aula de linguagem" (MONTEIRO, 1930b, p. 47). A escola deveria criar oportunidades para os alunos utilizarem seus saberes: na apresentação de ideias, na conversa, na argumentação e discussão acerca de assuntos de seu interesse; nas "opportunidades freqüentes e numerosas para 
as creanças exprimirem claramente os seus pensamentos; na "livre manifestação de pensamentos, interrogando-as, sobretudo pedindolhes a opinião, suscitando discussões entre ellas, conversando com ellas longamente sobre assumptos que as interessam". Somente por essa abordagem as crianças "farão uso da língua e aprenderão a pensar sobre as coisas e emitir claramente as suas oppiniões, defendendoas com coragem, explicando-as com firmeza". Esperava-se que as crianças desenvolvessem sua capacidade de expressão, que a escola permitisse que falassem "abundantemente, não as perturbando com corrigendas a toda hora, mas reparando nos defeitos e erros para corrigil-os depois" (REVISTA DO ENSINO, 1930a, p. 27-28).

Essa preocupação com o ensino contextualizado da linguagem, atrelado aos interesses e necessidades expressivas dos alunos, incluía a leitura, a oralidade e também a escrita. Em 1930, a Revista do Ensino defende que a escrita de composições escolares não poderia tornar-se um suplício para as crianças, que se angustiavam em busca de assuntos sobre os quais escrever. $\mathrm{O}$ artigo indica a necessidade de dar sentido ao ato de escrever, associar a escrita com os usos orais da linguagem e evitar que as composições se tornassem mera obrigação escolar. Assim, a revista recomenda a escrita de diários contextualizados na vivência das crianças, com registro das "peripécias, aventuras e reveses de sua vida cotidiana"; "todo exercício de linguagem deve ser, portanto, antes de tudo, um exercício de pensamento e um exercício falado" (REVISTA DO ENSINO, 1930b, p. 9-11). A revista ainda defendia a necessidade de romper com o verbalismo e o ensino mecânico, transformando a escola em espaço de trabalho, em que o aluno aprenderia por meio de sua ação (REVISTA DO ENSINO, 1930c, p. 12).

Reafirmando a linguagem como instrumento de comunicação, em 1933, Abgar Renault considera que, "não haverá exagero em affirmar-se que uma aula — seja de que disciplina seja — deve ser, primeiro de tudo, um modelo, senão uma obra prima de expressão". O professor ainda considera que o estudo da gramática deveria ocorrer no contexto de uso da língua (RENAULT, 1933, p. 15-16).

$\mathrm{Na}$ cidade de Montes Claros foram identificadas representações semelhantes, disseminadas pelo jornal Gazeta do Norte. Para Idoleta Maciel, aluna do Curso de Aplicação da Escola Normal, o vocabulário da criança era "uma bagagem caseira e às vezes muito viciada" de conhecimento, que precisava ser ampliado para tornar-se "preciso e claro". No entanto, "este augmento não deve ser feito por meio de listas de palavras, porque as que não têm uso corrente na vida são facilmente esquecidas" (MACIEL, 1933, p. 02). 
Nas concepções de Jenny Canella, também aluna do Curso de Aplicação da Escola Normal, cabia à escola redirecionar os conhecimentos, considerar as experiências e conhecimentos linguísticos da criança, corrigi-los, ajustá-los e ordená-los. "A criança não vae aprender uma língua differente, um novo idioma; vae ser redirigida, pela professora no sentido de se lhe corrigir, ajustar e ordenar a experiência verbal que traz de casa" (CANELLA, 1933, p. 01).

Em sua missão educativa, os artigos publicados pela Gazeta do Norte pretendiam produzir mudanças nas práticas escolares de leitura, colocando ênfase no interesse como recurso para mobilizar a atividade da criança. São concepções pedagógicas que concebiam o desejo como força motriz mais poderosa do que a coação e a imposição. Interesse que deveria ser utilizado em todas as atividades escolares, incluindo o trabalho com a linguagem oral, os conhecimentos sobre a língua, a escrita e a leitura. Caberia à escola renovar os métodos de ensino, de forma que a linguagem pudesse ser utilizada como mediação, instrumento de expressão, mas também fosse considerada como objeto sistemático de ensino. Por apropriar-se de ideias de sua época e acreditar no poder da leitura reflexiva, a Gazeta do Norte considerava importante mudar os métodos e recursos de ensino, de forma a garantir a formação de leitores e produzir mudanças nos usos da leitura.

\section{LIVROS E LEITURA DE HISTÓRIA COMO MEDIAC̣ÃO E INTERDIC̣ÃO NO ENSINO}

Como discutimos anteriormente, a renovação das práticas de ensino da leitura era condição para garantir a alfabetização e a inserção dos alunos no mundo da cultura escrita. Ao discutir essa crença no poder da leitura, Hébrard (1996) considera que todas as políticas de alfabetização e leitura guardam um otimismo pedagógico inabalável: "elas conhecem apenas uma modalidade, universal, da leitura, aquela que, por sua transparência, permite ao livro, pura mensagem, transformar a cera mole que imaginamos ser o leitor" (1996, p. 36). No entanto, conforme o autor, é necessário considerar que toda tentativa de educação através da escrita pode ser desviada de seus fins, seja porque os grupos sociais apoderam-se por contágio das práticas da escrita, ou porque o saber ler conduz às "más leituras" (HÉBRARD, 1996).

A modernidade pedagógica proposta pelo movimento da Escola Nova reafirma essa crença no poder do livro e da leitura. Conforme Vidal (2000), no contexto escolanovista, a leitura assume papel de destaque na formação intelectual dos educandos- de simples depositário da cultura universal o livro passa a ser visto como fonte de experiência. 
Nas representações disseminadas pela Escola Nova, o desejo, o interesse e o prazer da criança são compreendidos como molas propulsoras da atividade e da busca pelos livros. Nos discursos escolanovistas, a leitura era essencial, dado o potencial educativo dos livros e a possibilidade de adesão da criança que, encontrando prazer, se envolveria com o texto, independente de cobranças e imposições, formando-se como leitora de diferentes tipos e gêneros textuais. Segundo Vidal (2001):

O discurso escolanovista não se ocupou, apenas em normatizar o livro, atentando para seu aspecto material e de conteúdo. Uma explosão de falas sobre a leitura apontava para uma nova sensibilidade. A leitura prazerosa, muitas vezes identificada com a literatura, poderia ser reencontrada no trabalho e na escola. Abolido o livro-texto, a que se escravizavam os escolares, despertar-se-ia no aluno novo prazer por ler: aventura intelectual. Uma pluralidade de textos oferecia-se à descoberta (VIDAL, 2001, p. 207-208).

Nessas representações estava implícita a crença na capacidade dos livros em alterar comportamentos, por falarem ao coração do leitor pela via da sensibilidade, da emoção, do envolvimento com os textos e as histórias. E aí se situava o "perigo da leitura", posto que nem todos os livros eram considerados adequados aos leitores em formação.

No contexto montes-clarense, por associar-se à Escola Normal local e fazer adesão ao movimento escolanovista, o jornal Gazeta do Norte incluiu os livros e a leitura literária como tema de discussão. Nas publicações do jornal, as duas vertentes de compreensão discutidas por Hébrard (1996) foram consideradas: revelaram inabalável crença no poder da leitura e também discutiram um possível mau uso e as influências negativas dos livros e histórias.

Ainda em 1925, o jornal Gazeta do Norte defende que as mães deveriam assumir o seu papel, não apenas como "mães physicas, mas mães moraes" - tarefa que requeria a disponibilização de tempo para os filhos, para contar-lhes histórias edificantes, aprimorando-lhes a alma e o coração pela leitura.

Fiquemos certas de que, se roubarmos alguns minutos do dia dos nossos affazeres e também das nossas futilidades, que as temos e bastante, para nos dedicarmos a aprimorar, aformosear a alma e o coração dos nossos filhinhos, se tomarmos encantador encargo de ler, nas horas vagas alguma história edificante, contos escolhidos, às creancinhas, fazendo depois comentários e explicações, veremos quão surprehendentes resultados obteremos em pouco tempo. Lembremonos, queridos patrícios, do tempo da nossa infância, do sublime encanto que encontrávamos naquellas horas de doce intimidade, de soffreguidão com que ouvíamos as lindas histórias que nos contava a vovó, a titia ou a preta velha. Quem não conserva, até a morte, doces recordações dessa quadra inesquecível?! Em vez de deixarmos à soltas, os nossos filhinhos pelas ruas, pelo campo de foot-bal, pelo jardim, sabe Deus por onde mais, porque não os reunimos todos à roda para os instruir e entreter com histórias e contos proveitosos? (JORNAL GAZETA DO NORTE, 1925, p. 01). 
Pela perspectiva apontada, a leitura era compreendida como prática social, também orientada para finalidades não escolares. A mãe, autora do artigo, percebia a leitura como tecnologia e possibilidade de mediação, por meio da qual se poderia atingir determinados fins, aos quais fez adesão e para os quais apresenta argumentos de defesa. Imbuída das representações que circulavam naquela época, a mãe prescrevia novos usos para o livro e defendia a transformação dos comportamentos das crianças pela leitura. Os livros e a leitura se constituíam como meios para a produção de uma nova sociabilidade, retirando as crianças do pernicioso espaço da rua, para inseri-la no espaço doméstico controlado pela mãe-educadora.

Ao analisar essas práticas propostas, percebemos que as atenções da mãe-educadora não focalizavam apenas a escolha de livros edificantes, mas havia uma preocupação prescritiva em relação aos modos de ler. $\mathrm{O}$ ato de ler deveria seguir-se de comentários e explicações, pelos quais se encaminharia a compreensão da criança, orientando o seu olhar e garantindo os efeitos positivos das histórias. Ao sugerir que as mães lessem para seus filhos, a autora do artigo generaliza e universaliza as condições que lhe possibilitaram tornarse leitora, atribuindo às demais as mesmas condições de possibilidade de tornarem-se mediadoras.

Ao analisar a proposta de se comentar as histórias lidas é possível perceber uma preocupação com a não transparência na relação do leitor com os textos. Por compreender que o texto inscrevese diversamente em seus leitores, a matéria indicava estratégias de leitura que visavam impor uma ortodoxia do texto e neutralizar a liberdade do leitor. Ao sugerir que as mães leitoras explicassem o texto, a intenção era de controle da interpretação, garantindo-se que os sentidos produzidos pelas crianças se equivalessem aos sentidos pretendidos pelos adultos que mediavam a leitura.

Isso porque a diversidade de significações produzidas para um texto depende das competências dos leitores, de suas expectativas e disposições, mas dependem igualmente das maneiras como os leitores leem os textos. O jornal Gazeta do Norte compreendia a leitura não apenas como "audição de uma palavra leitora", usando expressão de Chartier (1990, p. 124). A mãe, autora da matéria publicada pelo jornal, entendia que, ao ouvir, o leitor-criança não era passivo em sua atividade, produzindo significações que precisavam ser controladas. O leitor mediador proposto não era um repetidor do texto e a prática de leitura sugerida aproxima-se das leituras escolares e prescritivas, que visam inculcar valores e "incorporar nos indivíduos os gestos necessários ou convenientes” (CHARTIER, 1990, p. 135). 
No contexto montes-clarense, o jornal Folha do Norte, em 1930, afirma as possibilidades transformadoras do homem pela via das leituras. "Assim como o corpo cresce pelo alimento, o espírito, o sentimento e a vontade crescem e fulguram pela leitura". E assim, "no livro ou no opúsculo, na revista ou no jornal, quantas vezes a intelligencia, ainda embrionária ou entenebrecida, adquire uma vida de luz, de sentimento e de fé que nos maravilha". Ainda segundo o jornal, a leitura era capaz de transformar o leitor - ao "inocular-se adentro, muito adentro do ser psiquico, tornando-o outro, modificando-o, aprimorando-o, emfim, fazendo dele - tantas vezes! - um herói ou um santo. Pode dizer-se uma segunda criação" (JORNAL FOLHA DO NORTE, 1930, p. 02).

Essas representações apontam para o perigo inscrito na leitura e nos livros. Por constituir uma faceta da renovação proposta pela Escola Nova, não apenas a leitura,a audição de histórias, a seleção de textos e as formas de ler, como também os perigos das más leituras, foi tematizado pela Revista do Ensino em diferentes oportunidades. Em 1926, Claudio Brandão lamenta que os livros destinados à leitura ainda se distanciavam do ideal pedagógico. "Muitos delles, além da feitura antiesthetica, peccam pela escolha dos trechos e dos assumptos e pela distribuição dos mesmos" (BRANDÃO, 1926, p. 6).

Em 1929, Firmino Costa considera que a relação positiva com os livros dependia da atuação docente. "Si a professora não sabe amar os livros, si não alimenta a sua intelligencia com o estudo, si enriquece o seu corpo e deixa pobrezinho o seu espírito, então, ella poderá ensinar a ler, não há duvida, mas seu ensino não terá dado ao alumno o amor da leitura" (COSTA, 1929, p. 43). Em 1930, o professor sugere aos professores primários mineiros a narração de histórias e a recitação de poesias como "aperitivo" para os alunos lerem bons livros. Em suas palavras, "inspire aos alumnos o amor da leitura, dando-lhes exemplo desse amor, reflectido nas licções que lhes ministra" (COSTA, 1930, p. 65).

Ainda em 1930, Catharina Silveira considera que, ao despertar nos alunos o amor pelos livros, era necessário alertá-los, "falar sobre as desvantagens e perigos que os máos livros constituem despertando nos alumnos a aversão a tudo quanto puder mancharlhes a consciência e perverter-lhes o coração" (SILVEIRA, 1930, p. 40). Já em 1933, o hábito da leitura é apresentado como solução para o "perigo das horas vagas", pois a leitura, além de ser uma inigualável fonte de conhecimentos, é capaz de "embevecer e elevar os homens" (REVISTA DO ENSINO, 1933, p. 02). 
Ainda na Revista do Ensino, Adherbal Alvarenga, no ano de 1933, destacou o cuidado do leitor em "não lêr toda obra que lhe cái à mão". Dadas as possíveis influências negativas de determinados materiais, "não ler às vezes é mais útil do que lêr. Os romances frívolos, as doutrinas exóticas e originais, os autores que se não recomendam pela correição da fórma, pureza da linguagem e elevação de sentimentos, devem ser banidos de nossas estantes" (ALVARENGA, 1933, p. 64).

Essas representações negativas sobre a qualidade estética de determinadas obras revelam a tensão instaurada entre prescrever e proscrever leituras e livros - preocupação contextualizada nos discursos e práticas das décadas de 1920-1930, que discutiu o perigo inscrito em certos livros. A discussão em torno da prescrição de leituras educativas foi identificada em pesquisas realizadas por Vidal (2001). Ao investigar a proposta de reforma empreendida pela Escola Normal do Rio de Janeiro na década de 1930, a autora afirma ser este um espaço-tempo institucional, em que se apostava na escola e em seu poder de transformação cultural, sendo que a formação de professores se produzia na tensão entre prescrições de leitura, modos de ler e utilizar o livro (VIDAL, 2001).

Uma faceta desse "perigoso" envolvimento do leitor com os livros foi discutida por Paiva $(1997,2000)$, que investigou a censura aos romances - censura compreendida como uma das dimensões do discurso católico sobre a leitura. Em seu estudo é realizada uma incursão na censura instaurada no início do século XX, a partir da atuação do Frei Pedro Sinzig, que elaborou e publicou um guia composto de críticas a um significativo número de livros, classificando-os, julgandoos, indicando-os ou vetando-os, conforme se apresentassem como leitura sadia ou perigosa à formação das moças.

Discutindo historicamente a questão, Abreu (2000) afirma que, no século XVIII, chegou-se a imaginar que a leitura pudesse oferecer riscos à saúde. $\mathrm{O}$ esforço continuado para ler um texto poderia prejudicar a visão, produzir esgotamento dos nervos, dificuldades digestivas, irritabilidade e uma série de outros problemas. No entanto, os problemas físicos advindos do excesso de leitura não eram os piores. Maior cuidado inspiravam as leituras que apresentavam perigos para a alma, aquelas que colocavam em risco a moral. Dizia-se que os livros divulgavam ideias falsas, fazendo-as parecer verdadeiras, estimulavam demasiadamente a imaginação, combatiam o pudor e a honestidade (ABREU, 2000). 
Em síntese, a retomada histórica dos livros e da leitura aponta para representações não consensuais e muitas vezes conflitantes, que sinalizam para as vantagens e perigos inscritos nos textos e nas práticas desenvolvidas pelos leitores.

\section{CONSIDERAÇ̃̃ES FINAIS}

Com o presente artigo discutimos práticas de ensino da leitura, apontando para a centralidade da alfabetização nos discursos sobre modernidade e desenvolvimento. Lançando um olhar inquiridor sobre o passado foi possível perceber que, desde o final do século XIX, há uma preocupação com a alfabetização e a educação da população. No entanto, os anos de 1920-30 revelam uma ampliação do debate, em que os discursos pedagógicos são atravessados pelos princípios da Escola Nova, passando a defender o desenvolvimento de habilidades que visavam à leitura funcional. No âmbito da escola, a leitura passa a ser compreendida como condição para investigação, pesquisa e aquisição de conhecimentos.

No contexto da cidade de Montes Claros, de campanha de conscientização, nos últimos anos da década de 1910, as ações do jornal Gazeta do Norte deslocam-se para uma discussão pedagógica do ensino da leitura. Assim, a partir dos últimos anos de 1920, as representações disseminadas indicam que, mais do que a alfabetização, pretendia-se desenvolver a capacidade de leitura reflexiva dos textos e inserir os leitores no mundo da cultura. No contexto de influências exercidas pela Escola Nova, a leitura assume a função de expressão de sentimentos e pensamentos e também considera a necessidade de atrelar o ensino ao interesse dos alunos e de contextualizar a realização das atividades de escrita, leitura, oralidade e gramática às situações de uso. Para efetivar as mudanças pretendidas, são disseminados conhecimentos relativos ao ensino da leitura e da escrita. As professoras são orientadas sobre a utilização de métodos e materiais, sobre a seleção de livros e as formas de ler.

Lançando nosso olhar para o momento presente percebemos que essas discussões dialogam com questões atuais que colocam foco nos usos sociais da leitura e da escrita e na possibilidade de sua utilização para a mudança social. A emergência de uma preocupação com a funcionalidade da leitura dialoga com questões relativas ao uso social da leitura, que ganha espaço no momento contemporâneo e tem sido compreendida com o processo de alfabetizar letrando. 


\section{FONTES DOCUMENTAIS}

ALVARENGA, A. A arte de ler. Revista do Ensino: órgão oficial da Inspetoria Geral da instrução. Ano VII. n. 92.15 de julho de 1933.

BRANDÃO, C. O ensino da leitura e do vocabulário. Revista do Ensino: Órgão Oficial da Inspetoria da Instrução. Belo Horizonte. Ano II. n. 10. Janeiro de 1926.

CANELA, C. Progresso da leitura infantil em Montes Claros. Gazeta do Norte. Ano XX. n. 1065, 17 de julho de 1937.

CONTE, A. Porque a Escola Nova é uma revolução pedagógica. Gazeta do Norte. Ano XVI. n. 912. 05 de maio de 1933.

COSTA, F. O ensino da leitura. Revista do Ensino: Órgão Oficial da Inspetoria da Instrução. Belo Horizonte Ano IV. n. 29. janeiro de 1929.

COSTA, F. Curso de aperfeiçoamento para o professorado primário. Methodologia de historia e de Instrucção Moral e Cívica. Prof. Firmino Costa. Revista do Ensino: órgão oficial da Inspetoria Geral. Ano V. n. 44. Abril de 1930.

JORNAL FOLHA DO NORTE. Escrever não é perverter. Ano I. n. 16, 04 de maio de 1930.

JORNAL GAZETA DO NORTE. A. Das mães de família. Ano VII. n. 377, 12 de setembro de 1925.

LAMBERT, L. Cantos escolares. Revista do Ensino: órgão oficial da Inspetoria Geral da instrução. Ano VII. n. 87-88. mai/ago/1933.

MACIEL, I. Columna pedagógica. A linguagem como instrumento de communicação. Gazeta do Norte, Ano XV, nº 856, 25 de março de 1933.

MONTEIRO, L. S. Curso de Aperfeiçoamento para o professorado primário: methodologia de língua pátria. Revista do Ensino: Órgão Oficial da Inspetoria da Instrução. Belo Horizonte. Ano V. n. 43. Março de 1930.

MONTEIRO, L. S. Curso de aperfeiçoamento para o professorado primário. Methodologia de língua pátria. Aulas da professora Lucia Schimidt Monteiro, sintetizadas pela Revista do Ensino. Revista do Ensino: órgão oficial da Inspetoria Geral da Instrução. Ano V. n. 44. Abril de 1930b.

OLIVEIRA, J. O systema Decroly. Revista do Ensino: Órgão Oficial da Inspetoria da Instrução. Belo Horizonte Ano III. n. 26. Outubro de 1928.

RAYMUNDO NETTO, J. Escola Activa - Liberdade e disciplina. Revista do Ensino: órgão oficial da Inspetoria Geral da instrução. Ano V. n. 44. Abril de 1930.

RENAULT, A. Discurso de paraninfo às diplomandas da Escola Normal de Juiz de Fora. Revista do Ensino: órgão oficial da Inspetoria Geral da Instrução. Ano VII. n. 79. $1^{\circ}$ de janeiro de 1933. 
REVISTA DO ENSINO: órgão oficial da Inspetoria Geral da Instrução. O ensino da língua. Ano V. n. 43. março de 1930, 1930a.

REVISTA DO ENSINO: órgão oficial da Inspetoria Geral da Instrução. Diário - o que é. Ano V. n. 43. março de 1930, 1930b.

REVISTA DO ENSINO: órgão oficial da Inspetoria Geral. Mãos a obra. Ano V. n. 41. jan.1930, 1930c.

REVISTA DO ENSINO: órgão oficial da Inspetoria Geral da instrução. Ano VII. n. 90-91. $1^{\circ}$ de julho de 1933.

SANTOS, H. Columna pedagógica. O pré-livro e a globalização. Gazeta do Norte. Ano XV. n. 855, 18 de março de 1933.

SILVEIRA, C. Amor à leitura. Como suscitaes em vossos alumnos o amor à leitura? Revista do Ensino: órgão oficial da Inspetoria Geral da Instrução. Ano V. n 43. março de 1930.

\section{REFERÊNCIAS}

ABREU, M. Prefácio: percursos da leitura. In: ABREU, M. (org.). Leitura, história e história da leitura. Campinas, SP: Mercado das Letras: Associação de Leitura do Brasil; São Paulo: Fapesp. p. 09-18, 2000.

CERTEAU, M.A invenção do cotidiano: artes de fazer. Petrópolis: Vozes. V. 01, 1998.

CHARTIER, R. (1990). História Cultural: entre práticas e representações. Trad. Maria Manuela Galhardo. Rio de Janeiro: Berthand do Brasil, 1990.

CHARTIER, A.-M. Práticas de leitura e escrita: história e atualidade. Belo Horizonte: Ceale; Autêntica, 2007.

FRADE, I. C. A. da S. Escolha de livros de alfabetização e perspectivas pedagógicas do ensino da leitura. In. BATISTA, A. A. G. e COSTA VAL, M. da G. (org.). Livros de alfabetização e de português: os professores e suas escolhas. Belo Horizonte: Ceale; Autêntica, 2004.

FRADE, I. C. A. da S.e MACIEL, F. I. P. O Livro de Lili em Minas Gerais: hegemonia didática e suas influências. In: FRADE, I. C. A. da S.e MACIEL, F. I. P. (org.). História da alfabetização: produção, difusão e circulação de livros (MG/RS/MT - Séc. XIX e XX). Belo Horizonte: UFMG/FAE. p. 95-116,2006.

GRAFF, H. J. Os labirintos da alfabetização: reflexões sobre o passado e o presente da alfabetização. Porto Alegre: Artmed, 1994.

HÉBRARD, J. O autodidatismo exemplar. Como Jamerey-Duval aprendeu a ler? In: CHARTIER, R. (org.). Práticas de leitura. São Paulo: Estação Liberdade. p. 35-74,1996.

LOURENÇO FILHO, M. B. Introdução ao estudo da escola nova: bases, sistemas e diretrizes da Pedagogia contemporânea. $12^{\mathrm{a}}$ ed. São Paulo: Melhoramentos; Rio de Janeiro: Fundação Nacional de Material Escola, 1978. 
PAIVA, A. A Voz do veto: a censura católica à leitura de romances. Belo Horizonte: Autêntica, 1997.

PAIVA, A. A leitura censurada. ABREU, Márcia (org.). Leitura, história e história da leitura. Campinas, SP: Mercado das Letras: Associação de Leitura do Brasil; São Paulo: Fapesp. p. 411- 426, 2000.

VIDAL, D. G. Livros por toda parte: o ensino ativo e a racionalização da leitura nos anos 1920 e 1930 no Brasil. ABREU, M. (org.). Leitura, história e história da leitura. CampinasSP: Mercado das Letras: Associação de Leitura do Brasil; São Paulo: Fapesp, 2000.

VIDAL, D. G. O exercício disciplinado do olhar: livros, leituras e práticas de formação docente no Instituto de Educação do Distrito Federal (1932-1937). Bragança Paulista: Editora da Universidade de São Francisco, 2001.

ZICMAN, R. B. História através da imprensa: algumas considerações metodológicas. Projeto História - Revista do Programa de Estudos Pós-graduação em História e do Departamento de História. São Paulo: PUC/SP. p. 89-102, 1985.

NOTA

${ }^{1} \mathrm{O}$ artigo é resultante de pesquisa de doutorado desenvolvida junto à Universidade Federal de Minas Gerais (UFMG) e contou com financiamento da Fundação de Amparo à Pesquisa do Estado de Minas Gerais (FAPEMIG), a quem agradecemos.

Submetido: 13/09/2016

Aprovado: 28/08/2017

Contato:

Geisa Magela Veloso

Universidade Estadual de Montes Claros (UNIMONTES) Av. Dr. Ruy Braga. S/N. Vila Mauriceia. Montes Claros $|\mathrm{MG}|$ Brasil CEP 39.401-089 